\title{
PERFORMANCE-ADJUSTED LIFE YEARS MAY SUBSTITUTE FOR QUALITY-ADJUSTED LIFE YEARS IN COST-EFFECTIVENESS ANALYSIS FOR ELDERLY PATIENTS WITH ADVANCED LUNG CANCER
}

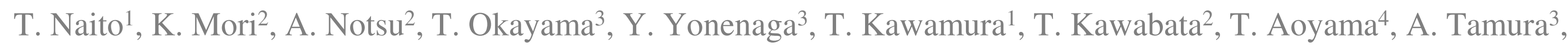

H. Murakami ${ }^{1}$, H. Kenmotsu ${ }^{1}$, A. Ono ${ }^{1}$, K. Nakashima ${ }^{1}$, H. Kobayashi ${ }^{1}$, S. Omori ${ }^{1}$, K. Wakuda ${ }^{1}$, N. Mamesaya ${ }^{1}$, E. Miyawaki ${ }^{1}$, T. Miyawaki ${ }^{1}$, T. Takahashi ${ }^{1}$.

${ }^{1}$ Division of thoracic oncology, ${ }^{2}$ Clinical Research Center, ${ }^{3}$ Rehabilitation medicine, ${ }^{4}$ Nutrition, Shizuoka Cancer Center, Shizuoka, Japan.

e-Poster presentation: No. MASCC9-0547, San Francisco, June 2019

\section{Introduction:}

Quality-adjusted life years (QALYs) are usually estimated using the quality of life (QOL) scale. However, a long-term collection of questionnaire and complex utility analysis become a burden on both patients and researchers. The aim of this study is to explore whether performance status (PS) could be a substitute for QOL scale in cost-effectiveness analysis.

\section{Methods:}

We prospectively recruited patients aged $\geq 70$ years with newlydiagnosed advanced non-small-cell lung cancer scheduled to initiate chemotherapy (Trial registration number,

UMIN000012845). All patients provided written informed consent. EuroQol 5 Dimension questionnaire and ECOG-PS, graded from 0 to 5 , was obtained every 12 weeks. The utility value for PS was calculated as $0.2 \times(5-P S)$. The mean cumulative medical costs ( $¥$, Japanese yen) for QALY and performance-adjusted life years (PALY) were calculated and compared.
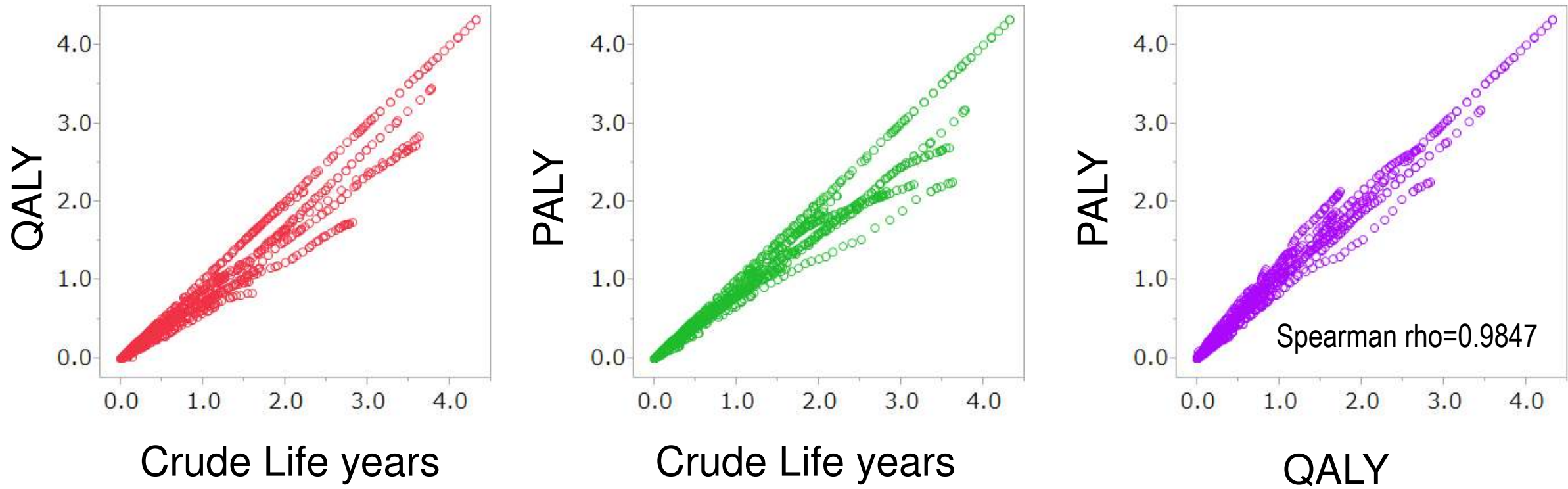

Cumulative cost per person (Japanese yen)

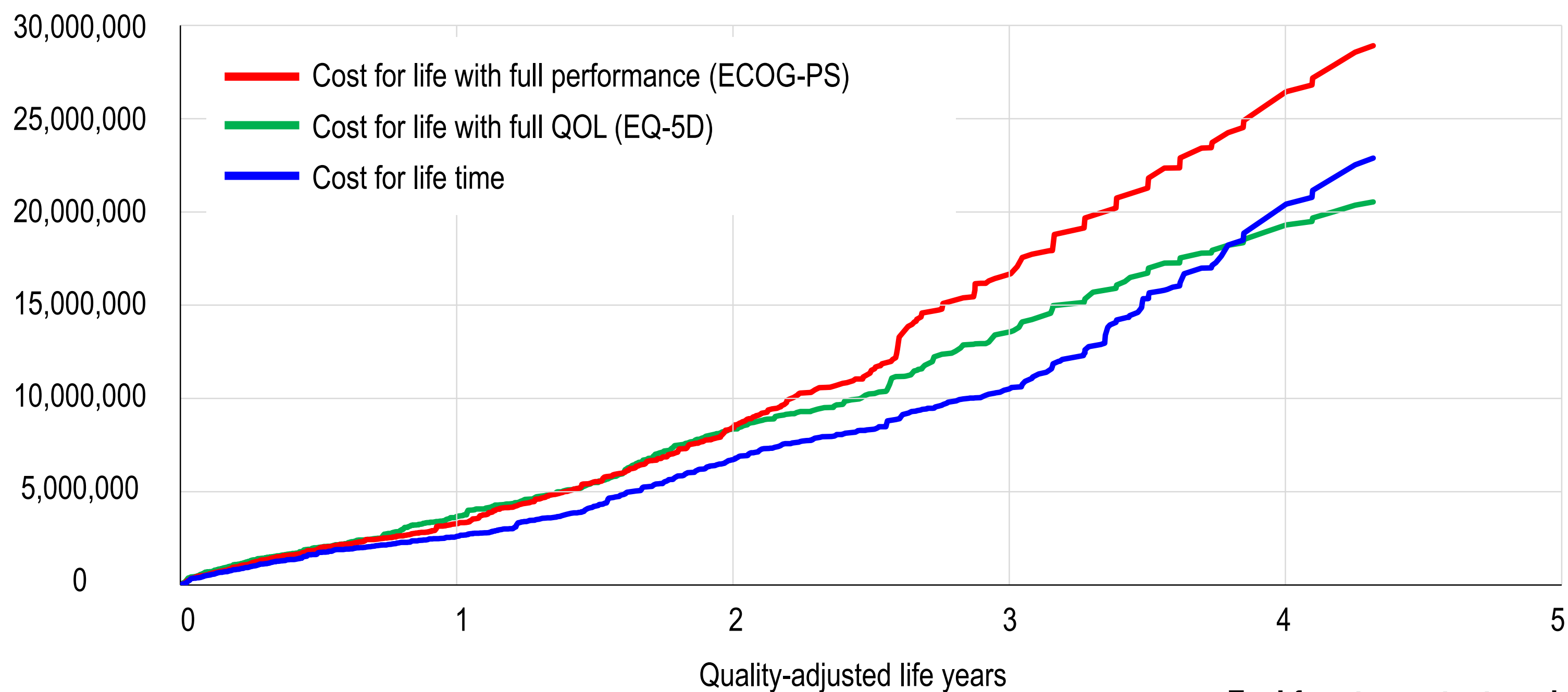

Feel free to contact me by e-mail: t.naito@scchr.jp 